khối u và mức độ liên quan giữa u và các cấu trúc lân cận. Các dấu hiệu trên CHT như chèn ép tủy sống, ngấm thuốc sau tiêm là những yếu tố quan trọng để phân biệt UTOS và các tổn thương khác.

\section{TÀI LIỆ THAM KHẢO}

1. K. K. Koeller and R. Y. Shih, 'Intradural Extramedullary Spinal Neoplasms: RadiologicPathologic Correlation', RadioGraphics, vol. 39, no. 2, pp. 468-490, Mar. 2019, doi:10.1148/rg. 2019180200.

2. L. L. Mechtler and $K$. Nandigam, 'Spinal Cord Tumors', Neurologic Clinics, vol. 31, no. 1, pp. 241-268, Feb. 2013, doi: 10.1016/j.ncl.2012.09.011.

3. K. Abul-Kasim, M. M. Thurnher, P. McKeever, and $\mathbf{P}$. C. Sundgren, 'Intradural spinal tumors: current classification and MRI features', Neuroradiology, vol. 50, no. 4, pp. 301-314, Apr. 2008, doi: 10.1007/s00234-007-0345-7.
4. Pham Ngọc Hoa, 'Đặc điểm hình ảnh cộng hưởng từ u tế bào schwann và u màng não trong màng cứng ngoài tủy', $Y$ học thành phố Hồ Chí Minh, 2009.

5. A. M. Quiles Granado, 'A Comprehensive Review of Intraspinal tumors: Diagnostic, classification and radio-pathologic correlation.', p. 4057 words, 2013, doi: 10.1594/ECR2013/C-2112.

6. V. K. Dasarju, S. Sree, M. S. Kikkeri, B. Shireesha, N. Pallavi, and Ch. S. Kumar, 'Magnetic Resonance Imaging in Spinal Tumors', IJCMSR, vol. 5, no. 1, Mar. 2020, doi: 10.21276/ijcmsr.2020.5.1.50

7. S. K. Panda, B. Nayak, M. Panigrahi, and P. Das, 'MRI Evaluation of Intramural Tumors of Spine in Adult and Pediatric Population- A Study at Tertiary Care Centre', p. 6.

8. J. Y. Chung, J. J. Lee, H. J. Kim, and H. Y. Seo, 'Characterization of Magnetic Resonance Images for Spinal Cord Tumors', Asian Spine J, vol. 2, no. 1, p. 15, 2008, doi: 10.4184/ asj. 2008.2.1.15.

\title{
KHẢO SÁT THỂ TÍCH TUYẾN TIỀN LIÊTT Ở NAM GIỚI TRÊN 45 TUỔI TẠI BỆNH VIỆN ĐẠI HỌC Y HÀ NộI
}

\author{
Nguyễn Hoài Bắc ${ }^{1,2}$, Hạ Hồng Cường², Hoàng Long1
}

\section{TÓM TẮT}

Nghiên cứu được thực hiên trên 2.867 nam giới trên 45 tuổi đến khám tại Khoà Nam học và $Y$ học giới tính bệnh viện Đại học $Y$ Hà Nội nhằm khảo sát thể tích tuyến tiền liệt và mối liên quan giữa thể tích tuyến tiền liệt với các triệu chứng đường tiểu dưới. Kết quả cho thây thể tích tuyến tiền liệt trung bình là $24,2 \mathrm{ml}$. Kích thước tuyến tiền liêt tăng theo tuổi và tăng cao ở nhóm bệnh nhân có triệu chứng đường tiểu dưới. Sau 10 năm thể tích tuyến tiền liệt sẽ tăng lên $4,3 \mathrm{ml}(\mathrm{p}<$ $0,001)$. Mô hình hồi quy logistic đa biến về giá trị dự đoán các triệu chứng đường tiểu của tuổi và thể tích tuyến tiền liệt cho thấy cứ tăng lên $10 \mathrm{ml}$ thể tích tuyến tiền liệt thì: tỷ số khả dĩ $(\mathrm{OR})$ có triệu chứng đường tiểu dưới tăng lên 1,2 lần $(p<0,001)$, tỷ số khả dĩ $(O R)$ có hội chứng kích thích tăng lên 1,2 lần ( $p$ $<0,001)$, tỷ số khả dĩ (OR) có hội chứng tắc nghẽ̃n tăng lên 1,3 lần $(p<0,001)$. Qua nghiên cứu này chúng tôi thấy trên quần thể nam giới trên 45 tuổi đến khám tại bệnh viện Đại học Y Hà Nội thì thể tích tuyến tiền liệt có liên quan với tuổi và các triệu chứng đướng tiểu dưới và thể tích tuyến tiền liệt là một yếu tố độc lập có giá trị dự đoán sự xuất hiện của triệu chứng đường tiểu dưới.

Tư khóa: thể tích tiền liệt tuyến, triệu chứng đường tiểu dưới, u phì đại tuyến tiền liệt.

\section{${ }^{1}$ Trường Đại học Y Hà Nội,}

Bênh viên Đai hơ Y Hà Nôi.

Chịu trách nhiệm chính: Nguyễn Hoài Bắc

Email: nguyenhoaibac@hmu.edu.vn

Ngày nhận bài: 22.10.2020

Ngày phản biện khoa học: 26.11.2020

Ngày duyệt bài: 7.12.2020

\section{SUMMARY \\ CHARACTERISTIC OF PROSTATE VOLUME AND THE RELATIONSHIP WITH LUTS IN MEN UPPER 45 YEARS OLD}

we conducted a study to evaluate the characteristicsof prostate volume on 2,867 man above 45 years old, who visited theAndrology and Sexual Medicine Dept in Hanoi Medical University Hospitalto find out the relationship betwen prostate volume and lower urine tract symptoms. The study showed that the mean prostate volume was $24.2 \mathrm{ml}$, which slightly increased in size (56.4\% of patients ranged from 20 to $40 \mathrm{ml}$ ). For every 10 years, prostate volume increases of $4.3 \mathrm{ml}$. Benign prostate hyperplasia has a considerable effect on the lower urinary tract symptoms in patients who hadprostate volumeabove $40 \mathrm{ml}$. Prostate volume has a predictive value for lower urinary tract symptoms in men over 45 years of age. For every $10 \mathrm{ml}$ increase in prostate volume, the likelihood of lower urinary tract symptoms increased by 1.2 times.

Keyword: prostate volume, lower urinary track symptoms, benign prostate hyperplasia.

\section{I. ĐẶT VẤN ĐỀ}

Tuyến tiền liệt là một trong các tuyến sinh dục phụ của nam giới có nhiệm vụ bài tiết tinh dịch và kháng nguyên đặc hiệu tuyến tiền liệt (PSA). Tiên liệt tuyến được hình thành từ tuần thứ 13 trong thai kì và phát triển dưới tác động của nôi tiết testosterone của cơ thể. Nằm ngay sát cổ bàng quang, ôm quanh đoạn niệu đạo nên tuyến tiền liệt được cho là có liển quan trực 
tiếp đến sự lưu thông của dòng nước tiểu từ bàng quang ra ngoài qua niệu đạo [6]. Ở người trưởng tuyến tiền liệt có hình elip hay hình hạt dẻ, với kích thước trung bình 20-25ml[4].

Người ta cho rằng, dưới tác động của testosterone, tuổi càng cao thì thể tích tuyến tiền liệt càng lớn. Khi tuyến tiền liệt càng lớn sẽ gây ra môt loạt các triêu chứng rối loan tiểu tiện ở nam giới, gọi là hội chứng đường tiểu dưới (LUTS). Tuy nhiên trên thực tế người ta vẫn gặp những bệnh nhân có kích thước tuyến tiền liệt nhỏ nhưng mức độ LUTS lại nặng hoặc ngược lại có những bệnh nhân có kích thước tuyến tiền liệt lớn nhưng lại không có LUTS hoặc triệu chứng rất nhẹ. Việc nghiên cứu về đặc điểm của tuyến tiền liệt và các triệu chứng LUTS giúp cho thây thuốc lâm sàng có những định hướng để tìm nguyên nhân khác gây triệu chứng LUTS ngoài tuyến tiền liệt. Để từ đó thẩy thuốc có những lựa chọn điều trị phù hợp cho bệnh nhân. Trên thế giới có nhiều nghiên cứu về LUTS và mổi liên quan tới tuyến tiền liệt bởi nó không chỉ ảnh hưởng rất lớn đến sinh hoạt, công việc, kinh tế, sức khỏe tình dục mà còn tới tinh thần của người bệnh ở mọi lứa tuổi, đặc biệt là nam giới > 45 tuổi[5].

Tại Việt Nam có rất ít nghiên cứu về mối liên quan giữa thể tích của tuyến tiền liệt với LUTS trên số liệu là nam giới Việt Nam. Vì vậy, chúng tôi thực hiện nghiên cứu này với mục tiểu là

1- Khảo sát thể tích tuyến tiền liệt ở nam giới trên 45 tuôi tai Bênh viên Đại học Y Hà Nôii.

2- Tìm hiểu mối liên quan giữa thể tích tuyến tiền liệt với các triệu chứng đường tiểu dưới.

\section{II. ĐỐI TƯỢNG VÀ PHƯƠNG PHÁP NGHIÊN CỨU}

2.1. Đối tượng nghiên cứu: Nam giới trong độ tuổi trên 45 , đến khám vì LUTS, có kết quả siêu âm đánh giá thể tích tuyến tiền liệt khoảng thời gian từ tháng 1 năm 2014 đến tháng 12 năm 2019 tại phòng khám Nam học - Bệnh viện Đại học $Y$ Hà Nội, loại trừ các trường hợp có bệnh lý ác tính.

2.2. Phương pháp nghiên cứu: Nghiên cứu mô tả cắt ngang, cỡ mẫu thuận tiện

Thể tích tuyến tiền liệt bằng được xác định siêu âm qua ổ bụng (Transabdominal ultrasonography-TAUS). Chiều dài, chiều cao, chiều rộng của tuyến tiền liệt được xác định trên siêu âm trong trạng thái bàng quang căng nước tiểu. Thể tích tuyến tiền liệt được tính theo công thức: $V$ (thể tích của tuyến tiền liệt) $=\Pi / 6$ (= $0,5236) \times$ chiều cao $(H) \times$ chiêu rộng $(W) \times$ chiều dài $(\mathrm{L})$. Phì đại lành tính tuyến tiền liệt
(BPE) được định nghĩa là thể tích tuyến tiền liệt $\geq 20 \mathrm{~mL}$ [2]

Xử lý số liệu bằng phần mềm $R$ phiên bản 3.6.1 cho hệ điều hành Windows.Kết quả được coi là có ý nghĩa thống kê với giá trị $p<0,05$.

III. KẾT QUẢ NGHIÊN CứU

3.1. Đặc điểm chung của nhóm nghiên cứu

Bảng 1: Đặc điểm của 2.867 đôî́ tượng tham gia nghiên cứu

\begin{tabular}{|c|c|c|}
\hline & n (\%) & $\begin{array}{c}\text { Trung bình } \\
\text { (SD) } \\
\text { Trung vi }\end{array}$ \\
\hline Tuổi & & $\begin{array}{c}56,1(8,18) \\
55,0\end{array}$ \\
\hline $45-54$ & $1387(48,4 \%)$ & \\
\hline $55-64$ & $1038(36,2 \%)$ & \\
\hline $65-74$ & $361(12,6 \%)$ & \\
\hline$\geq 75$ & $81(2,8 \%)$ & \\
\hline
\end{tabular}

Không có triệu chứng đường tiếu dưới $1986(69,3 \%)$

\begin{tabular}{|c|c|c|}
\hline \multicolumn{3}{|c|}{$\begin{array}{c}\text { Triệu chứng đường tiếu dưới } \\
881 \\
(30,7 \%)\end{array}$} \\
\hline Hội chứng kích thích & $746(26,0 \%)$ & \\
\hline Hội chứng tắc nghẽn & $296(10,3 \%)$ & \\
\hline Triệu chứng sau tiếu & $146(5,1 \%)$ & \\
\hline $\begin{array}{c}\text { Nồng đố PSA huyết } \\
\text { thanh (ng/ml) }\end{array}$ & & $\begin{array}{c}1,67(3,18) \\
0,97\end{array}$ \\
\hline$<4$ & $2465(93,7 \%)$ & \\
\hline $4-10$ & $124(4,7 \%)$ & \\
\hline$>10$ & $42(1,6 \%)$ & \\
\hline
\end{tabular}

${ }^{a}$ Trên 2.682 đối tượng; ${ }^{b}$ Trên 2.691 đối tượng; ' Trên 2.681 đối tượng;

d Trên 2.726 đối tượng; e Trên 2.828 đối tượng; ${ }^{f}$ Trên 2.631 đối tượng.

Tỷ lệ đối tượng nghiên cứu có triệu chứng đường tiểu dưới chiếm $30,7 \%$ trong đó hội chứng kích thích thường gặp nhất. Phần lớn bệnh nhân có nồng độ PSA huyết thanh trong giới hạn bình thường $<4 \mathrm{ng} / \mathrm{ml}(93,7 \%)$.

\section{2. Đặc điểm thể tích tuyến tiên liệt của} nhóm nghiên cứu

Bảng 2: Thể tích và phân nhóm theo kích thước tuyến tiền liệt trên siêu âm

\begin{tabular}{|c|c|c|}
\hline 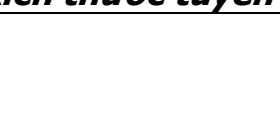 & n (\%) & $\begin{array}{l}\text { Trung bình } \\
\text { (SD) } \\
\text { Trung vi }\end{array}$ \\
\hline $\begin{array}{l}\text { Thế tích tuyến } \\
\text { tiền liệt (ml) }\end{array}$ & & $\begin{array}{c}24,2(10,5) \\
22,0\end{array}$ \\
\hline $\mathrm{V}_{\mathrm{TLT}}<20$ & $1047(36,5 \%)$ & \\
\hline $20 \leq \mathrm{V}_{\mathrm{TLT}}<40$ & $1616(56,4 \%)$ & \\
\hline $40 \leq \mathrm{V}_{\mathrm{TLT}}<60$ & $167(5,9 \%)$ & \\
\hline $60 \leq \mathrm{V}_{\mathrm{TLT}}<80$ & $27(0,9 \%)$ & \\
\hline $\mathrm{V}_{\mathrm{TLT}} \geq 80$ & $10(0,3 \%)$ & \\
\hline
\end{tabular}

SD: Độ lệch chuấn; $V_{T L T}$ : Thế tích tuyến tiền liệt 
Kích thước tuyến tiền liệt trung bình của đối tượng nghiên cứu là 24,2 ml. Tỷ lệ tăng nhẹ kích thước tuyến tiên liệt trên siêu âm (20 $\leq \mathrm{V}_{\mathrm{TLT}}<$ 40) là $56,4 \%$.

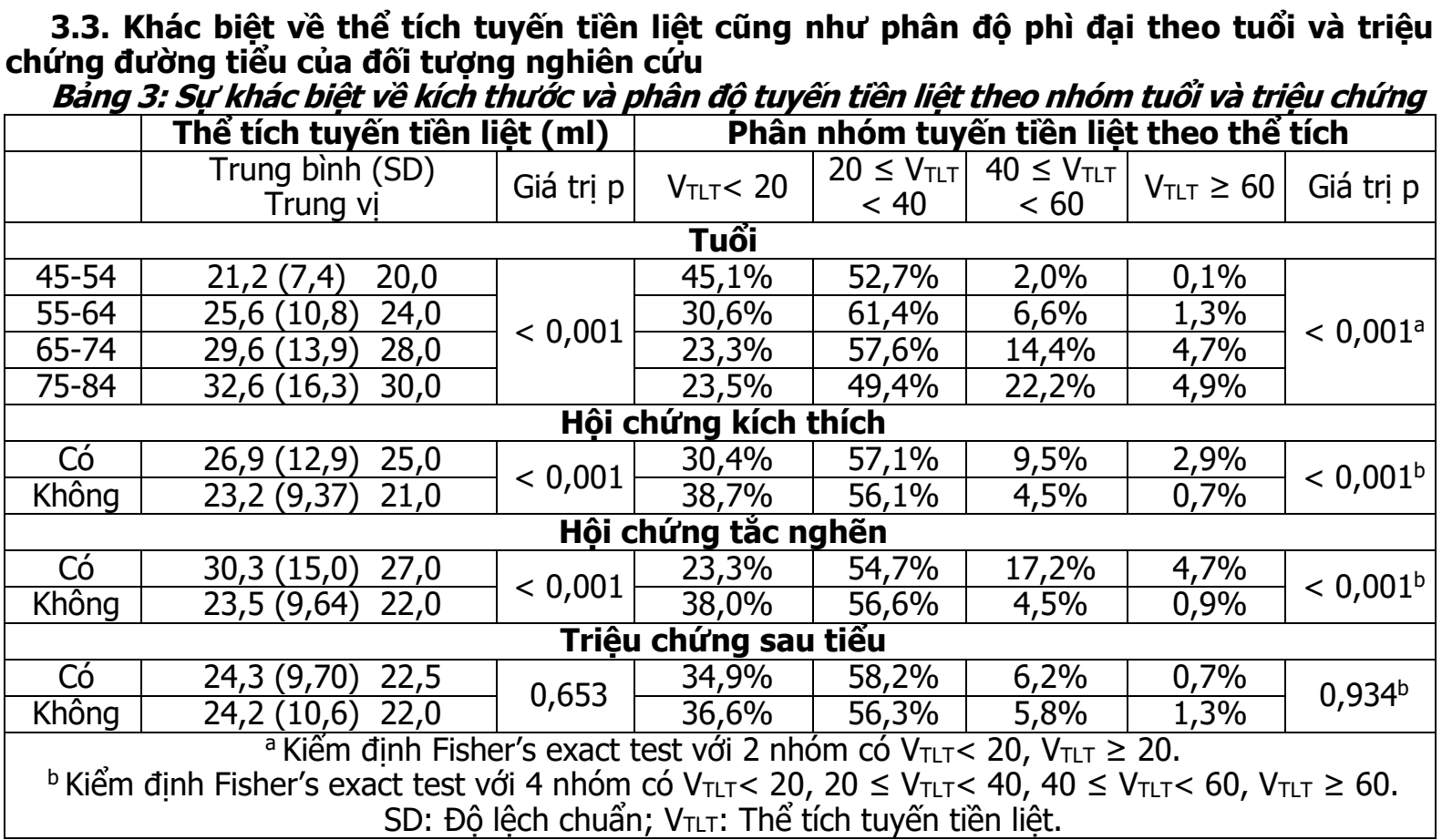

Thể tích tuyến tiền liệt có sự khác biệt giữa các nhóm tuổi, cũng như giữa bệnh nhân có và không có triệu chứng đường tiểu dưới. Tỷ lệ đối tượng có tăng kích thước tuyến tiền liệt trên siêu âm ( $V_{T L T} \geq 20 \mathrm{ml}$ ) tăng dân theo nhóm tuổi. Đặc biệt tỷ lệ bệnh nhân có kích thước tuyến tiền liệt trong khoảng 40 - $60 \mathrm{ml}$ và lớn hơn $60 \mathrm{ml}$ cao hơn một cách rõ rệt ở những đối tượng có triệu chứng đường tiểu dưới.

3.4. Mối liên quan giữa tuổi, thể tích tuyến tiên liệt và các triệu chứng đường tiểu dưới. Giữa tuổi và thể tích tuyến tiên liêt có mối liên quan yếu với hệ số rho của Spearman là $0,31$ ( $p<0,001)$. Mô hình hồi quy tuyến tính đơn biến cho thây, đối với nam giới trên 45 tuổi, cứ tăng lên 10 tuổi thì thể tích tuyến tiền liệt tăng lên 4,3ml ( $p<0,001)$.

Thể tích tuyến tiên liệt có giá trị dự đoán sự xuất hiện của các triệu chứng đường tiểu ở nam giới trên 45 tuổi độc lập với ảnh hưởng của tuổi. Mô hình hồi quy logistic đa biến về giá trị dự đoán các triệu chứng đường tiểu của tuổi và thể tích tuyến tiên liệt cho thấy cứ tăng lên $10 \mathrm{ml}$ thể tích tuyến tiền liệt thì: tỷ số khả dĩ (OR) có triệu chứng đường tiểu dưới tăng lên 1,2 lân ( $p<$ 0,001), tỷ số khả dĩ (OR) có hội chứng kích thích tăng lên 1,2 lần $(p<0,001)$, tỳ số khả dĩ (OR) có hội chứng tắc nghẽn tăng lên 1,3 lân ( $p<0,001)$.

\section{BÀN LUÂNN}

Kích thước tuyến tiên liêtt được cho là chịu sự tác động của nhiều yếu tố. Trong đó tuổi là yếu tố nguy cơ chính cho sự gia tăng kích thước tuyến tiền liệt. Quá trình lão hóa gây nên các biến đổi trong quá trình phân chia tế bào và sự cân bằng của các hormone trong tuyến tiên liệt. Ngoài ra, lão hóa còn liên quan đến sự gia tăng các phản ứng viêm và thoái hóa của các mạch máu nhỏ, dẫn đến tình trạng thiểu dưỡng và gia tăng stress oxy hóa. Điêu này tạo điêu kiện cho $\mathrm{BPH}$. BPH sẽ dẫn đến phì đại lành tính tuyến tiền liệt (BPE). BPE được xác định khi thể tích của tuyến tiên liệt (Prostatic volume-PV)>20ml[2]. Như vậy ở nam giới lớn tuổi, $B P H$ và $B P E$ là một tình trạng thường gặp.

Tuổi trung bình của nhóm nghiên cứu là 56,1 tuổi, với 48,1\% dưới 55 tuổi. Đa số có nồng độ PSA ở mức bình thường $(93,7 \%)$. PV trung bình của nhóm nghiên cứu là 24,2ml, khá tương đồng với kích thước tuyến tiên liệt của người châu Á $\left(29,2 \pm 14,3 \mathrm{~cm}^{3}\right)$ [3]; 63,5\% bệnh nhân có PV > $20 \mathrm{ml}$, trong đó chủ yếu là tăng nhẹ kích thước (56,4\% bệnh nhân có PVtừ $20-40 \mathrm{ml})$. Kết quả nghiên cứu của chúng tôi tương tự với tác giả Park khi nhận thây BPE xảy ra ở khoảng $42 \%$ nam giới từ 51-60 tuổi, $71 \%$ nam giới từ $61-70$ tuổi và $88 \%$ nam giới từ 81 tuổi trở lên [2]. 
Ngoài ra, chúng tôi cũng nhận thấy có mối liên quan giữa PV với tuổi. PV trung bình của nhóm tuổi 45-54 là 21,2ml, trong nhóm tuổi 5564 là $25,6 \mathrm{ml}$, trong nhóm tuổi $65-74$ là $29,6 \mathrm{ml}$, và trong nhóm tuổi 75-84 là 32,6ml. Tuổi càng cao thì tỷ lệ có $P V$ lớn càng nhiêu. Giữa tuổi và thể tích tuyến tiền liệt có mối tương quan yếu với hệ số Spearman Rholà $0,31(p<0,001)$. Mô hình hồi quy tuyến tính đơn biến cho thây, đối với nam giới trên 45 tuổi, cứ tăng lên 10 tuổi thì thể tích tuyến tiền liệt tăng lên $4,3 \mathrm{ml}(p<$ $0,001)$, tương đương $0,43 \mathrm{ml} /$ năm. Kết quả này hoàn toàn phù hợp với khảo sát sự thay đổi PV của nam giới châu Á, với tốc độ tăng PV trung bình hàng năm là $0,48 \mathrm{~cm}^{3}$, tương tự như tỷ lệ được báo cáo trong các nghiên cứu ở dân số Nhật Bản và Hàn Quốc $\left(0,3-0,6 \mathrm{~cm}^{3} /\right.$ năm), đặc biệt từ> 70 tuổi[3].

Trong nhóm nghiên cứu của chúng tôi, có thể thây sự khác biệt rất nhỏ về PV của nhóm bệnh nhân có LUTS (PV trung bình $=26,9 \mathrm{ml})$ và nhóm bệnh nhân không có LUTS (PV trung bình $=23,3$ $\mathrm{ml})$. Trong nhóm bệnh nhân có PV từ $20-40 \mathrm{ml}$, tỷ lệ bệnh nhân có LUTS và không có LUTS gần như tương đương nhau (58\% và 55,6\%).Sư khác biêt chỉ thây rõ trong nhóm PV từ 40-60ml, tỷ lệ bệnh nhân có LUTS gấp khoảng 2 lần bệnh nhân khổng có LUTS $(9,2 \%$ và $4,3 \%)$; và khác biệt rõ rệt trong nhóm PV > 60ml, khi tỷ lệ bênh nhân có LUTS cao gấp 5 lần bệnh nhân không có LUTS (3\% và $0,6 \%)$. Như vậy $\mathrm{BPH}$ chỉ thật sự có ảnh hưởng gây nên LUTS khi có thể tích lớn $(>40 \mathrm{ml})$.

BPH là một quá trình tăng sản (tăng số lượng tế bào) tuyến chứ không phải quá trình phì đại (tăng kích thước tế bào) tuyến. Phản ứng của bàng quang đối với sự tắc nghẽn là một sự thích nghi. Sự tắc nghẽn sẽ làm cho bàng quang tăng sinh collagen, phì đại cơ trơn, thay đổi thụ cảm thể áp lực của tế bào cơ trơn, suy giảm sự lan truyền tín hiệu liên kết giữa các tế bào cơ trơn, bất thường tín hiệu dẫn truyền canxi tế bào cơ trơn. Tất cả điều này làm mất tính ổn định và giảm khả năng co bóp và tống xuất của cơ trơn bàng quang, và là một trong những cơ chế bệnh lý gây nên các triệu chứng tắc nghẽn đường tiểu dưới. Ngoài ra, ngày càng có nhiêuu bằng chứng cho thấy tắc nghẽn có thể làm thay đổi sự chi phối của thân kinh trung ương với bàng quangs(giảm co bóp bàng quang, suy giảm chức năng xử lý trung tâm và thay đổi cảm giác trong bàng quang).Quá trình lão hóa cơ thể cũng dẫn đến những thay đổi sinh học của bàng quang, làm tăng các tác động của sự cản trở. Chính vì vậy, nhiêuu trường hợp bệnh nhân có các biểu hiện của LUTS ngay cả khi PV vẫn nằm trong giới hạn bình thường[6].

Trong LUTS, triệu chứng tắc nghẽn là các triệu chứng chính, chiêm $2 / 3$ các trường hợp[1]. Với nhóm bệnh nhân có $P V<40 \mathrm{ml}$ thì tỷ lệ bệnh nhân có triệu chứng tắc nghẽn và không có triệu chứng tắc nghẽn là tương đương nhau; trong nhóm PV từ 40-60ml, tỷ lê bệnh nhân có triệu chứng tắc nghẽn gấp khoảng 4 lần bệnh nhẩn không có triệu chứng tắc nghẽn $(17,2 \%$ và $4,5 \%)$; còn trong nhóm PV > 60ml, tỷ lệ bệnh nhân có triệu chứng tắc nghẽn gấp hơn 5 lần bệnh nhân không có triệu chứng tắc nghẽn $(4,7 \%$ và $0,9 \%)$. Khảo sát trong nhóm bệnh nhân có triệu chứng kích thích và triệu chứng sau tiểu cũng cho kết quả gần tương tự với sự khác biệt giữa có và không có triệu chứng ở nhóm bệnh nhân có PV>40ml.

Các kết quả trên cho thấy, PV có giá trị dự đoán sự xuất hiện LUTS ở nam giới trên 45 tuổi độc lập với ảnh hưởng của tuổi. Mô hình hồi quy logistic đa biến về giá trị dự đoán các triệu chứng đường tiểu của tuổi và thể tích tuyến tiển liệt cho thây PV cứ tăng lên $10 \mathrm{ml}$ thì khả năng xuất hiện LUTS tăng lên 1,2 lần, khả năng xuất hiện hội chứng kích thích tăng lên 1,2 lần, và khả năng xuất hiện có hội chứng tắc nghẽn tăng lên 1,3 lần.

\section{KẾT LUÂ̂N}

Tuổi trung bình của nhóm nghiên cứu là 56,1 tuổi, với $48,1 \%$ dưới 55 tuổi; và đa số có nồng độ PSA ở mức bình thường (93,7\%).

Thể tích tuyến tiền liệt trung bình của nhóm nghiên cứu là $24,2 \mathrm{ml}$, có liên quan với tuổi, cứ tăng lên 10 tuối thì $P V$ tăng lên $4,3 \mathrm{ml}(p<$ 0,001 ). Thể tích tuyến tiền liệt có giá trị dự đoán sự xuất hiện LUTS ở nam giới trên 45 tuổi độc lập với ảnh hưởng của tuổi. PV cứ tăng lên $10 \mathrm{ml}$ thì khả năng xuất hiện LUTS tăng lên 1,2 lần.

\section{TÀI LIÊU THAM KHẢO}

1. Chen, Jing-Liang và các cộng sự. (2019), "Precision medicine in the diagnosis and treatment of male lower urinary tract symptoms suggestive of benign prostatic hyperplasia", $\mathrm{Ci}$ ji yi xue za zhi $=$ Tzu-chi medical journal. 32(1), tr. 5-13.

2. Park, Hyun Jun và các cộng sự. (2013), "Urinary Tract Symptoms (LUTS) Secondary to Benign Prostatic Hyperplasia (BPH) and LUTS/BPH with Erectile Dysfunction in Asian Men: A Systematic Review Focusing on Tadalafil", The world journal of men's health. 31(3), tr. 193-207.

3. Park, Jee Soo và các cộng sự. (2019), "Impact of metabolic syndrome-related factors on the development of benign prostatic hyperplasia and lower urinary tract symptoms in Asian population", 
Medicine. 98(42), tr. e17635-e17635.

4. Tyloch, Janusz F. và Wieczorek, Andrzej Paweł (2017), "The standards of an ultrasound examination of the prostate gland. Part 2", Journal of ultrasonography. 17(68), tr. 43-58.

5. Yoo, Eun Sang và các cộng sự. (2011), "The impact of overactive bladder on health-related quality of life, sexual life and psychological health in Korea", International neurourology journal. 15(3), tr. 143-151.

6. Wein, Alan Jvà các cộng sự (2016), " Benign Prostatic Hyperplasia: Étiology, Pathophysiology, Epidemiology, and Natural History", CampbellWalsh Urology 4(Chapter 103), tr. 2425-2461.

\section{MộT Số ĐẶC ĐIỂM DỊCH TỄ HỌC SỐT XUẤT HUYẾT Ở KHÁNH HÒA 2017-2018}

\section{Vũ Xuân Nghĩa ${ }^{1}$, Nguyễn Văn Chuyên ${ }^{2}$, Nguyễn Quang Bình ${ }^{3}$, Nguyễn Hải Sâm ${ }^{2}$, Phan Quốc Hoàn ${ }^{1}$, Nguyễn Thị Hiền ${ }^{4}$}

\section{TÓM TẮT.}

Nghiên cứu được thực hiên 100 bệnh nhân mắc bênh sốt xuất huyểt trên địa phận Nha Trang, Khánh Hò̀a. Phương pháp nghiên cứu mô tả cắt ngang, labo. Kết quả nghiên cứu cho thây, tỉ lệ nhóm người mắc bệnh sốt xuất huyết tâp trung ở trẻ em $21 \%$ và người già $20 \%$. Nguyên nhẩn gây bệnh sốt xuất huyết có virus Dengue $9 \%$ khi phát hiện bằng test nhanh nsp1.

Tư khóa: Sốt xuất huyết, virus Dengue.

\section{SUMMARY}

\section{SOME CHARACTERISTICS OF HEMORRHAGE FEVER IN KHANH HOA 2017-2018}

The study was performed on 100 patients suffering from hemorrhagic fever in Nha Trang, Khanh Hoa. The method describes cross section, labo. Research results show that the proportion of people with hemorrhagic fever concentrates in children $21 \%$ and the elderly $20 \%$. Causes of hemorrhagic fever with dengue virus $9 \%$ when detected by rapid test nsp 1 .

Keywords: hemorrhagic fever, Dengue virus

\section{I. ĐĂT VẤN ĐỀ}

Khánh Hòa là một tỉnh ở vùng duyên hải cực Nam Trung Bộ, nằm trong khu vực khí hậu nhiệt đới xa van. Khánh Hòa Thường chỉ có 2 mùa rõ rệt là mùa mưa và mùa nắng. Mùa mưa ngắn, từ khoảng giữa tháng 9 đến giữa tháng 12, lượng mưa thường chiếm trên $50 \%$ lượng mưa trong năm. Những tháng còn lại là mùa nẳng. Nhiệt độ trung bình hàng năm của Khánh Hòa cao khoảng $26,7^{\circ} \mathrm{C}$, độ ẩm tương đối khoảng $80,5 \%$. Đây cũng coi là điều kiện môi trường, thời tiết khí hậu

\footnotetext{
${ }^{1}$ Bênh viện TWQĐ108

${ }^{2}$ Họ viện Quân $y$

${ }^{3}$ Bệnh viện Răng Hàm Mặt TW

${ }^{4}$ Đai hoc Dước Hà Nôi.

Chịu trách nhiệm chính: Vũ Xuân Nghĩa

Email: nghia69@gmail.com

Ngày nhânn bài: 27.10.2020

Ngày phản biên khoa học: 27.11.2020

Ngày duyệt bài: 9.12.2020
}

phù hợp với quá trình phát triển của mỗi, vector mang các mầm bệnh gây bệnh sốt xuất huyết.

Bệnh sốt xuất huyết thường gây bởi virus Dengue hay còn gọi sốt xuất huyết Dengue. Song những năm gần đây, tại Khánh Hòa cho thây tính chất phức tập của bệnh sốt xuất huyết về quy mô, tần số, mức độ trầm trọng của bệnh. Nguyên nhân gây bệnh sốt xuất huyết hiện nay tập trung vào 03 mầm bệnh chính là virus Dengue, Virus Chikungunya, virus Zika. Để làm sóng tỏ về nguyên nhân gây bệnh sốt xuất huyết ở Khánh Hòa, chúng tôi tiến hành nghiên cứu một số đặc điểm dịch tễ học của bệnh sốt xuất huyết, từ đó đánh giá việc lưu hành nguyên nhân gây bệnh sốt xuất huyết.

\section{II. ĐỐI TƯỢNG VÀ PHƯƠNG PHÁP NGHIÊN CỨU}

2.1. Đối tượng nghiên cứu: Gồm 100 bệnh nhân được chẩn đoán sơ bộ sốt xuất huyết trên địa bàn Nha Trang từ 2017-2018.

2.2. Phương pháp nghiên cứu. Thiết kế nghiên cứu nghiên cứu cắt ngang, labo, nhận xét đánh giá.

Xây dựng tiêu chuẩn lựa chọn bênh nhân sốt xuất huyết theo thứ tư ưu tiên: Xuất huyết (dấu hiệu dây thắt (+) hoặc xuất huyết tự nhiên); Sốt cao, kéo dài từ 2-7ngày. (lấy mẫu tốt nhất thường trong 5 ngày đầu khi khởi phát các triệu chứng đầu tiên); Đau đầu, đau cớ, đau khớp; Giảm tiểu câu < $100.000 / \mathrm{mm}^{3}$, Hematocrit tăng; Các bệnh nhân được chẩn đoán ngoài cộng đồng dựa vào test nhanh và Kit ELISA; Sống trong vùng có dịch lưu hành.

Phương pháp phát hiện virus bao gồm ELISA, Realtime RT-PCR, thực hiện theo hướng dẫn của nhà sản xuất.

2.3. Xử lý số liệu: phần mềm Exel.

2.4. Y đức: Những bệnh nhân đều chấp thuận tham gia nghiên cứu, mọi kết quả mang tính cá nhân được thông báo và bảo mật theo quy định. 